\title{
Technical Barriers to Trade in the European Union: Importance for Accession Countries
}

\author{
Paul Brenton, John Sheehy \\ and Marc Vancauteren
}

\begin{abstract}
With trade in industrial products between the EU and the CEECs now essentially free of tariff and non-tariff restrictions, the principal impact of accession to the EU on trade flows will be through access to the Single Market of the EU. A key element of this will be the removal of technical barriers to trade. In this paper we try and highlight the importance of technical barriers to trade between the EU and the various CEECs, distinguishing sectors according to the different approaches to the removal of these barriers in the EU: mutual recognition, detailed harmonisation (old approach) and minimum requirements (new approach). We utilise two sources of information on technical regulations: a sectoral classification from a previous study of the impact of the Single Market and our own detailed translation of EU product related directives into the relevant tariff codes. The analysis suggests that the importance of technical barriers varies considerably across the CEECs. The adjustment implications of access to the Single Market are likely to be greatest for those most advanced in their accession negotiations.
\end{abstract}




\section{Introduction}

EU imports of industrial products from the Central and Eastern European countries (CEECs) are now free of tariffs and quantitative restrictions. This implies that the impact of the accession of these countries to the EU on trade will be determined by the removal of contingent protection measures, such as, anti-dumping duties or undertakings, ${ }^{1}$ but more importantly by their access to the Single Market of the EU. The full incorporation of the CEECs into the Single Market will provide for the complete freedom of movement of goods produced in the CEECs throughout all of the existing 15 EU member countries and the new member states in Central and Eastern Europe. This will entail the removal of customs frontiers, and the associated costs of delays and documentation currently incurred when goods from the CEECs cross the EU border, equal access to government procurement contracts in EU countries, and the removal of barriers to trade imposed by differing technical regulations in the CEECs and in EU countries.

Previous analysis of the completion of the Single Market in the existing EU countries suggests that the removal of technical barriers to trade may be of great significance. CEC (1998) calculates that over 79 per cent of intra-EU trade may have been affected by technical regulations in 1996. In general, however, the issue of technical barriers to trade and their impact upon trade flows has received little attention in the literature on international trade despite the fact that it is recognised that these may constitute a substantial impediment to trade. This reflects in part problems relating to data. In many cases the impact of access to the Single Market has simply, and inadequately, been modelled as an ad hoc reduction in trade costs common across all suppliers. ${ }^{2}$

In this paper we look at the evidence concerning technical barriers to trade and try and identify their importance to trade between the CEECs and the EU. We use two alternative data sources. Firstly, we apply sectoral indicators of the presence of

\footnotetext{
${ }^{1}$ For an analysis of the impact of the removal of EU anti-dumping measures against the CEECs see Brenton (1999).

${ }^{2}$ For example, Gasiorek, Smith and Venables (1991) and Brenton and Winters (1992) in different exercises assume that the completion of the Single Market implies a 2.5 per cent reduction in trade costs for all EU members. More recently, Francois (1998), takes accession to the EU for CEECs to entail an across the board reduction in trade costs of 10 per cent.
} 
technical barriers and the particular approach to their removal adopted in the EU, as provided in the review of the impact of the Single Market in the EU (CEC (1998)). We use these to identify the coverage of CEECs exports to the EU of technical measures and also to look at the pattern of comparative advantages in these sectors. Secondly, we use our own transcription of EU directives in terms of their coverage of detailed products (8 digit $\mathrm{CN}$ codes). This allows us to look at the similarity of each CEECs exports to and imports from the EU of products subject to technical regulations in the EU. We start by briefly describing the approaches adopted in the EU to the removal of technical barriers to trade.

\section{The EU Approach to Technical Barriers to Trade}

\subsection{Sources of Technical Barriers to Trade}

Technical barriers to trade (TBT's) can arise whenever a producer may have to alter his/her product in order to comply with differing partner country requirements such as for health, safety, environmental and consumer protection issues. These requirements can be imposed by both governments (technical regulations) and non-governmental organisations (non-regulatory barriers, standards). The legal character of technical regulations distinguishes them from non-regulatory barriers or standards; namely, the latter are voluntary, not legally binding and arise from the self-interest of producers or consumers involved, for example, to improve the information in commercial transactions and ensure compatibility between products. The former mainly relates to either technical specifications or testing and certification requirements such that "the product actually complies with the specifications to which it is subjected (conformity assessment)"

Technical barriers therefore strike at the heart of business operations affecting business pre-production, production, sales and marketing policies. The need to adapt product design, re-organise production systems, multiple testing and certification costs can entail a significant cost (or technical trade barrier) for suppliers of exported goods to a particular country, the magnitude of which differs across products. The removal of TBTs at the Community level is a central tenet of the Single Market since it is crucial for the provision of equal conditions of market access throughout the whole of the European Economic Space. The removal of such barriers promotes trade and efficiency 
and serves to strengthen competition by undermining the fragmentation of the EU market.

\subsection{Instruments for removing TBT's}

The Community now has a widespread set of instruments to combat the marketsegmenting effect of technical trade barriers. EU policy related to standards, testing and certification requirements, is currently based upon two approaches: enforcement of the Mutual Recognition Principle (MRP) and if this fails, the harmonisation of technical standards in each member country. Each approach will now be discussed in turn.

\subsubsection{The Mutual Recognition Principle}

The basic EU approach has been to promote the idea that products manufactured and tested in accordance with a partner country's regulations could offer equivalent levels of protection to those provided by corresponding domestic rules and procedures. However, this often requires accreditation of testing and certification bodies and a mutual recognition arrangement (MRA) between bodies because member states often regulate for the same product risks in slightly different ways (or in the same way but requiring duplication of conformity assessment). 'Mutual Recognition' tends to apply where products are new and specialised and it seems to be relatively effective for equipment goods and consumer durables, but it encounters difficulties where the product risk is high and consumers or users are directly exposed.

\subsubsection{The Harmonisation Approach}

Where 'equivalence' between levels of regulatory protection embodied in national regulations can not be assumed, the only viable way to remove the TBT in question is for the member states to reach agreement on a common set of legally binding requirements. Subsequently, no further legal impediments can prevent market access of complying products anywhere in the EU market. EU legislation harmonising technical specifications has involved two distinct approaches, the 'old approach' and the 'new approach'. The old approach mainly applies to products (chemicals, motor vehicles, pharmaceuticals and foodstuffs) by which the nature of the risk requires extensive product-by-product or even component-by-component legislation and is carried out by means of detailed directives. 
In the main achieving this type of harmonisation has been slow for two reasons. First of all, the process of harmonisation became highly technical since it sought to meet the individual requirements of each product category (including components). This resulted in extensive and drawn-out consultations. Secondly, the adoption of old approach directives was based on unanimity in the Council. As a result the harmonisation process proceeded extremely slowly. Indeed the approach was ineffective since new national regulations proliferated at a much faster rate than the production of EC level directives on a limited set of products (Pelkmans (1987)).

It became increasingly recognised that there was a need to reduce the intervention of the public authorities prior to a product being placed on the market. Moreover, the decisionmaking procedure needed to be adapted in order to facilitate the adoption of technical harmonisation directives by a qualified majority in the Council. This has been done by the adoption of the 'new approach' and applies to products, which have "similar characteristics" and where there has been widespread divergence of technical regulations in EU countries. What makes this approach 'new' is that it only indicates 'essential requirements' and leaves greater freedom to manufacturers as to how to satisfy those requirements, dispensing with the 'old' type of exhaustively detailed directives.

The new approach directives provide for more flexibility than the detailed harmonisation directives of the old approach, by using the support of the established standardisation bodies, CEN, CENELEC and the national standard bodies. The standardisation work is achieved in a more efficient way, is easier to update and involves greater participation from industry. A further feature of the new approach is the use of market surveillance and the choice of attestation methods that are available: by self-certification against the essential requirements, by using generic standards or by using notified bodies for type approval and testing of conformity of type. We now proceed to assess the importance of technical regulations in the EU in terms of the amount of trade which is affected. 


\section{Technical Barriers and Trade between the EU and the CEECs}

\subsection{The Sectoral Incidence of Technical Barriers}

Here we utilise information on the sectoral incidence of technical barriers and the particular approach adopted by the EU to their removal. The data come from the detailed study undertaken for the Commission's review of the impact of the Single Market in the EU (CEC (1998)). This study provides information at the 3 digit level of the NACE classification (about 120 manufacturing industries) of whether trade is affected by technical regulations and the dominant approach used by the Commission to removal such barriers in the EU. For sectors where technical regulations affect trade, the study classifies them as those where the barriers are overcome using mutual recognition (MR), and those sectors where mutual recognition is insufficient or unsuitable so that either the old approach (OA) or the new approach (NA) to overcoming technical barriers is used. For these sectors it is assumed that all trade is affected by the technical regulations and by the identified approach to the removal of the barriers. There are however, a small number of sectors where a combination of approaches is identified. In the main, we ignore these in the analysis which follows.

\subsubsection{The Trade Coverage of Sectors Subject to Technical Regulations}

We start by showing the overall trade coverage of technical barriers in the EU and of the different approaches to their removal. In other words, we aggregate the imports of the EU (12) from different suppliers (each country's exports to the EU) across all the sectors which are not subject to technical barriers to trade. We then separately identify the proportion of total imports in sectors subject to old approach directives, new approach directives, mutual recognition, and finally a residual reflecting sectors where several approaches are relevant. ${ }^{3}$

In Figure 1a we first show the breakdown of EU imports in 1998 from existing EU members. This figure demonstrates that a very large proportion of intra-EU trade is in sectors affected by technical regulations. On average less than one quarter of intra-EU imports are in sectors where technical regulations are not important. The significance of these sectors ranges from around 38 per cent of EU imports from Greece to 18 per cent of EU imports from Germany and 13 per cent of EU imports from Ireland.

\footnotetext{
${ }^{3}$ Trade data according to the NACE classification were obtained from the COMEXT database.
} 
There is considerable variation across EU members in the share of trade affected by the different approaches to the removal of technical barriers. For example, sectors where mutual recognition is used comprise a relatively large share of EU imports from Ireland (43 per cent of total imports), Greece (33 per cent) and Portugal (32 per cent) but a small share of EU imports from Finland (7 per cent of the total), Sweden (13 per cent), Austria and Spain (both around 15 per cent). Sectors characterised by the new approach to the removal of technical barriers comprise a relatively large share of EU imports from Italy, Germany, Denmark Sweden and Austria but are less important in EU imports from Greece, Ireland, the Netherlands, Portugal and Spain. Sectors where the old approach applies comprise a relatively large share of EU imports from Spain, Sweden and Finland (over one third of the total) and are also of particular importance for France, Germany, Belgium, Netherlands, Portugal and Austria (a quarter or more of the total). Thus, the principal conclusions to be drawn from Figure 1a are of the overall importance of technical regulations to trade between EU countries and the variation across countries in the share of trade affected by the different approaches to the removal of the barriers caused by differing national regulations.

In Figure $1 \mathrm{~b}$ we present a similar breakdown of EU imports from the applicant countries in Central and Eastern Europe, also in 1998. Here again there is considerable diversity across countries. Over one third of EU imports from Bulgaria and Latvia in 1998 were in sectors where technical regulations do not pose significant barriers to trade. Examples of such sectors include certain non-ferrous metals, footwear, and sawing and processing of wood. In contrast, less than one fifth of EU imports from Hungary, Slovakia and Slovenia were in sectors free of trade restricting technical regulations in the EU. It is clear from the figure that products subject to new approach directives in the EU form a much larger share of exports to the EU of the Czech Republic and of Slovenia than for other CEECs. In this case the main sectors are those producing machinery. Old approach products are of greatest importance to Slovakia, Estonia and Hungary. For these countries the main sectors include motor vehicles and parts, prepared meats and petroleum products.

Figure 2 presents a ranking by country of the importance of each of the main categories of technical barriers in terms of the coverage of EU imports. Figure 2a shows that on 
average the products of sectors subject to old approach directives comprise a relatively small share of EU imports from non-member countries relative to intra-EU trade. Only for imports from Lithuania, Bulgaria and Romania does the share of old approach products fall below the average for extra-EU imports. In this sense the remaining CEECs are more similar to the existing EU countries than they are to non-member countries in terms of the importance of old approach products in their exports to the EU.

It is apparent from Figure $2 \mathrm{~b}$ that the products of sectors subject to new approach directives form a larger share of EU imports from the Czech Republic, Slovenia, Poland, Hungary, and Slovakia than of average EU imports from existing member states. For other CEECs such as Romania and Bulgaria, the share of new approach products does not differ substantially from that of EU member states such as France and the Netherlands. Mutual recognition sectors, such as, knitting and clothing industries, are particularly important in EU imports from the Balkan countries and Lithuania whilst they comprise a relatively small share of imports from the Czech Republic and Slovenia. Sectors where technical barriers are not significant are a relatively high share of EU imports from the Balkan and Baltic states but are much less important for Hungary, Slovenia and Slovakia. Again, the figures reinforce the conclusion of considerable diversity amongst the CEECs of the importance of sectors subject to technical regulations and of the share of sectors subject to the different approaches to the removal of technical barriers in the EU.

\subsubsection{The Evolution of Trade Subject to Technical Regulations in EU Imports from and Exports to the CEECs}

In Figure 3 we show the evolution of the shares of sectors subject to the various approaches in EU imports from those countries where data permit a ten-year perspective. The graphs for Poland and Hungary clearly show the declining share of sectors where technical barriers are not significant. In 1988 around 50 per cent of EU imports from Poland were of products where technical regulations are not a barrier to trade in the EU. By 1997 the share of such sectors had fallen to 27 per cent with the shares of new approach sectors and mutual recognition sectors rising. The share of old approach sectors remained fairly constant. For Hungary the share of sectors with no technical barriers fell from 34 per cent in 1998 to less than 18 per cent 10 years later. 
Here the share of new approach products increased from 10 to 15 per cent of the total and the share of mutual recognition products also increased, from 18 to 26 per cent. Again the importance of old approach sectors changed little.

For Bulgaria and Romania a very different picture emerges. For EU imports from both of these countries the share of sectors with no technical barriers to trade increased: from 37 to 42 per cent for Bulgaria and from 19 to 30 per cent for Romania. On the other hand, the share of old approach sectors collapsed, primarily during the period prior to 1992. Old approach sectors accounted for 24 per cent of EU imports from Bulgaria in 1988 but only 7 per cent in 1997. For Romania the share of these sectors fell from 35 per cent in 1988 to 3 per cent within the subsequent decade. In the case of Bulgaria this reflects a constant value of exports of old approach products amongst a growing value of total exports to the EU. For Romania, however, the value of exports of old approach products collapsed in the early 1990s, due primarily to a decline in exports of refined mineral oil products, motor vehicles and prepared meats. The share of new approach products in EU imports from these countries changed little over this period. The most notable change in share was that for mutual recognition products which increased from 31 to 46 per cent for Romania and from 16 to 25 per cent for Bulgaria.

Hence from the perspective of the importance of sectors subject to different approaches to technical regulations there have been major changes in the structure of EU imports from these CEECs since the onset of transition. The role that foreign direct investment has played in the increasing importance of new approach sectors in EU imports from Poland and Hungary would be an interesting topic for further research. This would help to make an assessment of the extent to which countries such as Bulgaria and Romania will move into these sectors if they are able to attract significant amounts of FDI in sectors such as engineering. The constant or declining shares of old approach products in EU imports from the CEECs suggests that there are not strong comparative advantages in these sectors in central and Eastern Europe, an issue to which we return below. 


\subsubsection{Comparative Advantages and Technical Barriers}

In Figure 4 we show the results of an analysis of revealed comparative advantage of each of the CEECs in their trade with the EU, again classifying sectors according to the approach adopted to technical barriers in the EU. Our index of revealed comparative advantage is defined as

$$
R C A_{i l}=\frac{\frac{x_{i l}}{\sum_{l=1}^{n} x_{i l}}}{\frac{\sum_{i=1}^{m} x_{i l}}{\sum_{l=1}^{n} \sum_{i=1}^{m} x_{i l}}}
$$

where $x_{i l}$ is the value of exports of sector 1 from country $i$ to the EU. There are $n$ products and $\mathrm{m}$ is the total number of countries exporting to the EU (including EU member countries). The numerator shows the share of a particular sector in the country's exports to the EU, whilst the denominator shows the share on this product in total EU imports. A value of the index in excess of one is taken to reveal a comparative advantage in the production and export of that sector.

In Figure 4 we group together sectors according to whether they are subject to old approach directives, new approach directives, mutual recognition or no significant barriers and then simply plot in descending order the value of the index of revealed comparative advantage for each of the NACE 3-digit sectors. ${ }^{4}$ The key issue we wish to highlight is the number of sectors within each of the four groups in which each of the CEECs reveals a comparative advantage in their trade with the EU.

In general these results suggest that for all of the CEECs there are relatively few old approach sectors where a comparative advantage in trade with the EU is revealed. For all of the CEECs relative efficiency is displayed in at most four of the 23 old approach sectors. This is suggestive that the accession of the CEECs and their access to the Single Market will not have a great impact upon EU imports of products from old approach sectors. In contrast, France reveals a comparative advantage (data not shown here) in 14

\footnotetext{
${ }^{4}$ To improve the presentation we have truncated the distribution with an upper level of five. In principal what matters is whether the index is greater than or less than one.
} 
of the old approach sectors. Thus, the main impact of accession may be to intensify competition in old approach sectors in CEEC markets.

With regard to new approach sectors the picture varies across the CEECs. Most of the CEECs reveal a comparative advantage in a limited number of new approach sectors but usually to a greater extent than in old approach sectors. However, for countries such as the Czech Republic and to a lesser extent Poland, Slovakia and Slovenia, comparative advantage in new approach sectors is more broadly based. The Czech Republic reveals a comparative advantage in all but two of the 19 new approach sectors. Poland appears to be a relatively efficient producer of products from 11 of the new approach sectors. Thus, this analysis suggests that if trade in new approach sectors between the EU and the CEECs is currently constrained by technical barriers to trade and the accession of the CEECs alleviates these barriers then competition in the EU market for these products may intensify. We return to this issue below when we look in more detail at the similarity of products exported by the CEECs and the EU countries.

It may be, of course, that technical barriers to trade in the EU are distorting these measures of comparative advantage so that we may be underestimating the comparative advantages of the CEECs in old approach, new approach and mutual recognition sectors. However, the barriers in the EU faced by the different CEECs are likely to be similar so that our analysis here may give a reasonable picture of the relative comparative advantages of the CEECs across sectors. In addition, the decline in the share of old approach sectors in CEEC exports to the EU shown in Figure 3 occurred with unchanged policies for these sectors in the EU: harmonised standards were already in place. This suggests that the decline reflects domestic factors in the CEECs and the loss of comparative advantage.

\subsection{Detailed Product Analysis of Old and New Approach Directives}

The sectoral approach used above assumes that all products within a sector are covered by technical regulations. In this section we report the results from using alternative information on technical regulations in the EU. Here we have studied old approach and new approach directives, or used secondary information which has already undertaken such a task, to identify the precise product codes that are covered by the relevant 
technical regulations. The product classification that we use is the detailed trade classification of the EU, the Combined Nomenclature, which permits a direct link to the available trade data. We translate the old and new approach directives to the relevant 8 digit tariff line codes that are covered. ${ }^{5}$

These data allow for a much more detailed analysis of the nature of the exports of the CEECs to the EU of products subject to technical regulations in the EU and the extent to which they may be competing with products produced by EU member countries. The more similar is the product composition of CEEC and EU exports subject to technical barriers the greater the potential impact of the removal of those barriers with accession to the EU. Here we assess the degree of overlap between EU imports from different sources by using the similarity index. This was first introduced by Finger and Kreinin (1979) to examine the potential of the GSP to divert trade: "If exports are dissimilar - i.e. subject to little or no 'commodity overlap' - then there is little scope for trade diversion". The similarity index is used here to compare the structure of EU imports from any one supplier, r, with that of any other supplier of imports to the EU market, $\mathrm{j}$,

$S_{r j}=\sum_{l=1}^{n} \operatorname{Min}\left(w_{r l}, w_{j l}\right) * 100$

where $\mathrm{w}_{\mathrm{rl}}$ is the share of product 1 in total EU imports from country $\mathrm{r}$, and $\mathrm{w}_{\mathrm{jl}}$ is the share of the same product in EU imports from country $\mathrm{j}$. The higher the value of the index the more similar are the two countries export structures. On the other hand, if products which are important in one country's exports are of little significance in the other country's exports, then the value of the index will tend towards zero.

Here we apply this index to assess the degree of similarity between flows of new approach products and then separately between flows of old approach products. That is we take all those 8 digit codes which have been identified as new approach products and then assess the degree of overlap between EU imports (and then exports) from different sources within the EU countries and the CEECs. We then repeat the exercise for old approach products. The results are summarised in Figure 5 for new approach products and Figure 6 for old approach products. We show separately, graphs for the similarity of EU imports from

\footnotetext{
${ }^{5}$ There are over 10000 codes in the EU classification.
} 
different sources with the intra-EU average, the similarity between EU exports to different sources and average intra-EU exports, and finally the similarity between each country's exports to and imports from the EU of new and then old approach products.

Figures 5a and 6a show that similarity with average intra-EU imports of new approach and old approach products is generally higher amongst the EU countries than for the CEECs. All of the CEECs exhibit a lower degree of similarity with intra-EU imports than is shown by imports from non-members countries on average. Figures $5 b$ and $6 b$ suggest a more narrow distribution of similarity indices for EU exports of new approach and old approach products. In other words the degree of similarity between the structure of products that the EU exports to the CEECs and average exports within the EU is much higher than the similarity between the products that the EU imports from the CEECs and average imports within the EU.

Since intra-EU exports are equivalent to intra-EU imports this implies that there is a low degree of similarity between EU imports from and EU exports to the CEECs of old approach and new approach products. This is shown more clearly in Figures 5c and 6c. Thus, for example, less than 10 per cent of Latvian exports of old approach and new approach products to the EU are matched by imports in similar product categories. For Bulgaria, Romania and Slovakia there is a degree of overlap of between 20 and 30 per cent. Thus, to a large degree these countries are exporting different products, amongst the new approach and old approach products, to the EU than they are importing from the EU. Amongst the CEECs the highest degree of similarity between exports to and imports from the EU is shown by Poland, Hungary and the Czech Republic where the degree of overlap lies between 30 and just over 40 per cent. This reflects in part country size. Small countries, such as Latvia, will tend to produce a narrower range of products than larger countries, such as Poland. However, the values of the similarity index for the CEECs are much lower than the apparent degree of similarity for EU members of similar size. This suggests that the adjustment implications of accession to the Single Market may not be as great as if the CEECs were competing more directly with EU countries in the same product segments. 


\section{Conclusions}

One of the, if not the most, important factor(s) affecting trade between existing EU members and new member states in central and eastern Europe will be the removal of technical barriers to trade. To date there has been little attempt to assess the importance of such barriers to trade between the EU and the CEECs. In this paper we have provided a very simple graphical analysis firstly using existing data sources of the sectoral incidence of technical regulations in the EU and then using our own translation of the detailed product coverage of old and new approach directives. The general conclusions we reach are:

- that there is considerable diversity across the CEECs in the importance of sectors subject to technical regulations in the EU. Broadly, those countries currently most advanced in their accession negotiations are those where technical regulations are more important for their exports to the EU. This is suggestive that adjustment to the Single Market will be greater in these countries compared to, for example, the Balkan countries, where sectors for which technical barriers are not significant are much more important. Thus, for Romania and Bulgaria a large share of their exports to the EU already faces market access conditions identical to those of existing EU members and where accession will have little direct impact. However, it is possible that the exports of these countries of products subject to technical regulations in the EU are being constrained by current access conditions and the lack of FDI into these countries.

- For all the CEECs there is little evidence from current trade flows of comparative advantage in sectors subject to old approach directives. For some of the CEECs, notably, the Czech Republic and Poland, a comparative advantage is revealed in a wide range of sectors subject to the new approach in the EU.

- For new approach products and for old approach products the CEECs generally exhibit a low degree of similarity between their exports to the EU and their imports from the EU. This is suggestive of different channels of specialisation within the group of new approach products and within the group of old approach products. This will tend to mitigate the adjustment implications of accession in both the CEECs and the existing EU member countries. 
This analysis has shown the importance of technical regulations to trade between the EU and the CEECs and some of the characteristics of such trade. It is apparent that the share of exports accounted for by products where there may be technical barriers to trade varies greatly across the CEECs. Thus, modelling the next enlargement as a common shock in all the CEECs does not appear to be appropriate. A key issue for further research is to proceed further and to identify the extent to which the application of technical regulations in the EU actually constrains imports from the CEECs. Alternatively, to be able to assess the extent to which trade will expand upon accession as technical barriers to trade are removed we need to understand much better how the removal of these barriers in the EU with creation of the Single Market affected intra-EU trade flows. 


\section{Bibliography}

Brenton, PA (1999) 'Anti-Dumping, Diversion and the Next Enlargement of the EU' Working Document 129, CEPS, Brussels

Brenton, PA and Winters, LA (1992) 'Estimating the International Trade Effects of "1992": West Germany', Journal of Common Market Studies, 30, 143-156

CEC (1998) 'Technical Barriers to Trade', Volume 1 of Subseries III Dismantling of Barriers of The Single Market Review, CEC, Luxembourg

Finger, J.M. and Kreinin, M.E. (1979), "A Measure of 'Export Similarity' and Its Possible Uses", Economic Journal, 89, 905-912.

Francois, JF (1998) 'Scale Economies, Imperfect Competition and the Eastern Expansion of the EU', in Brockmeier et al (eds), Economic Transition and the Greening of Policies, Wissenschaftsverlag Vauk Kiel KG: Kiel

Gasiorek, M, Smith, A and Venables, A (1991) 'Completing the Internal Market in the EC: Factor Demands and Comparative Advantage', in Winters, LA and Venables, AJ (eds) European Integration: Trade and Industry, CUP, Cambridge

Pelkmans, J (1987) 'The New Approach to Technical Harmonization and Standardization' Journal of Common Market Studies, 25, 249-69 

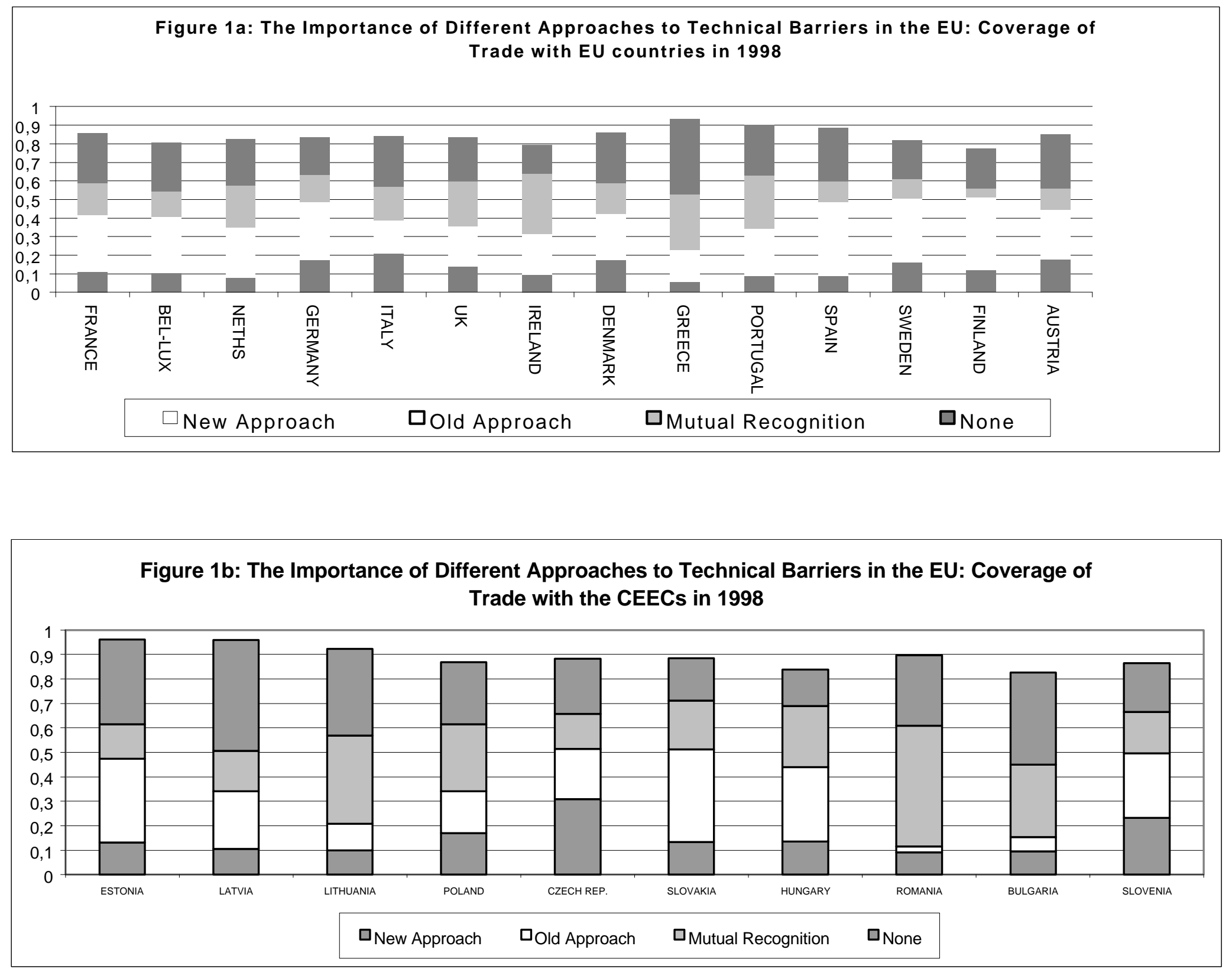

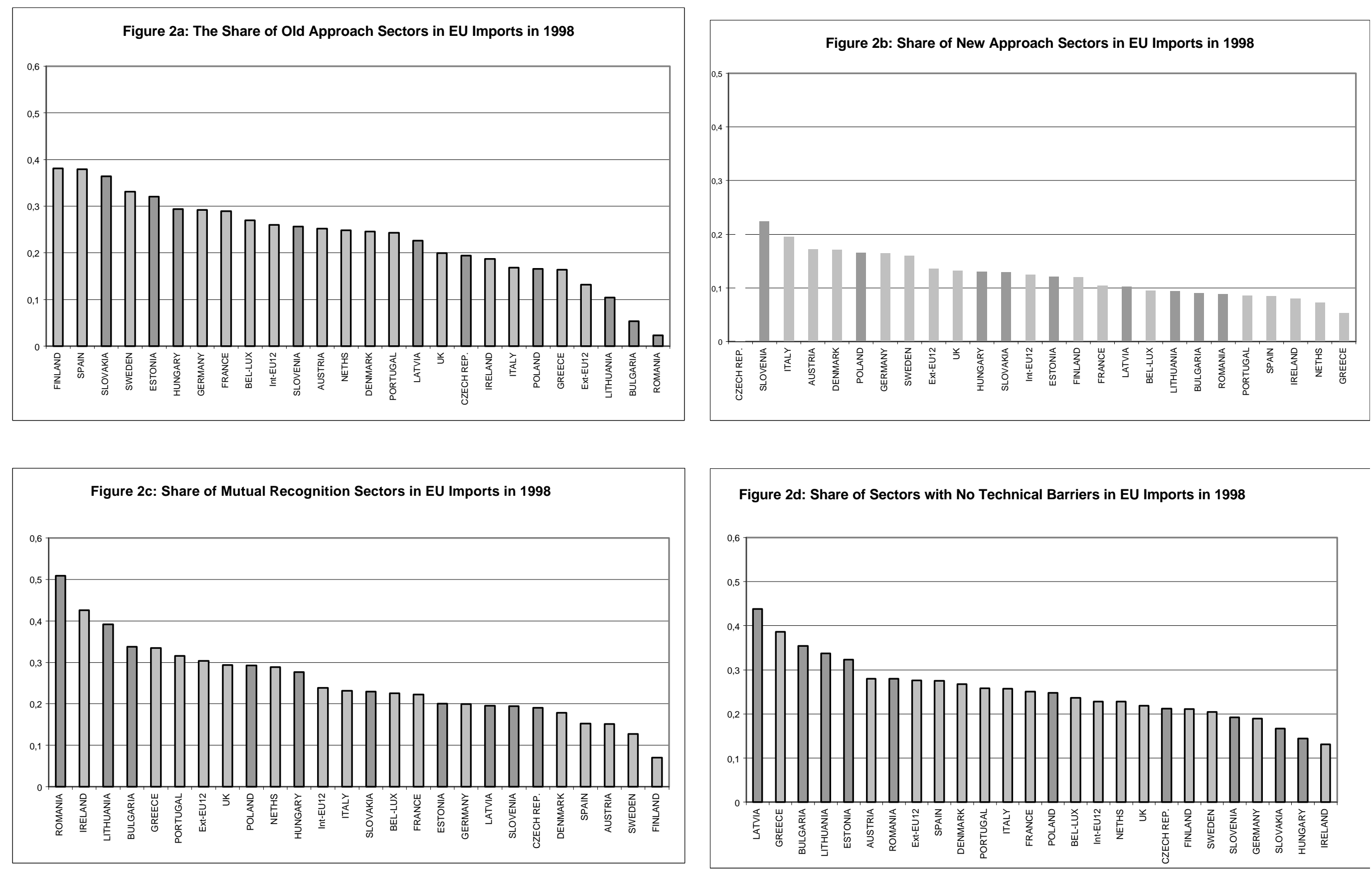

Figure 2d: Share of Sectors with No Technical Barriers in EU Imports in 1998

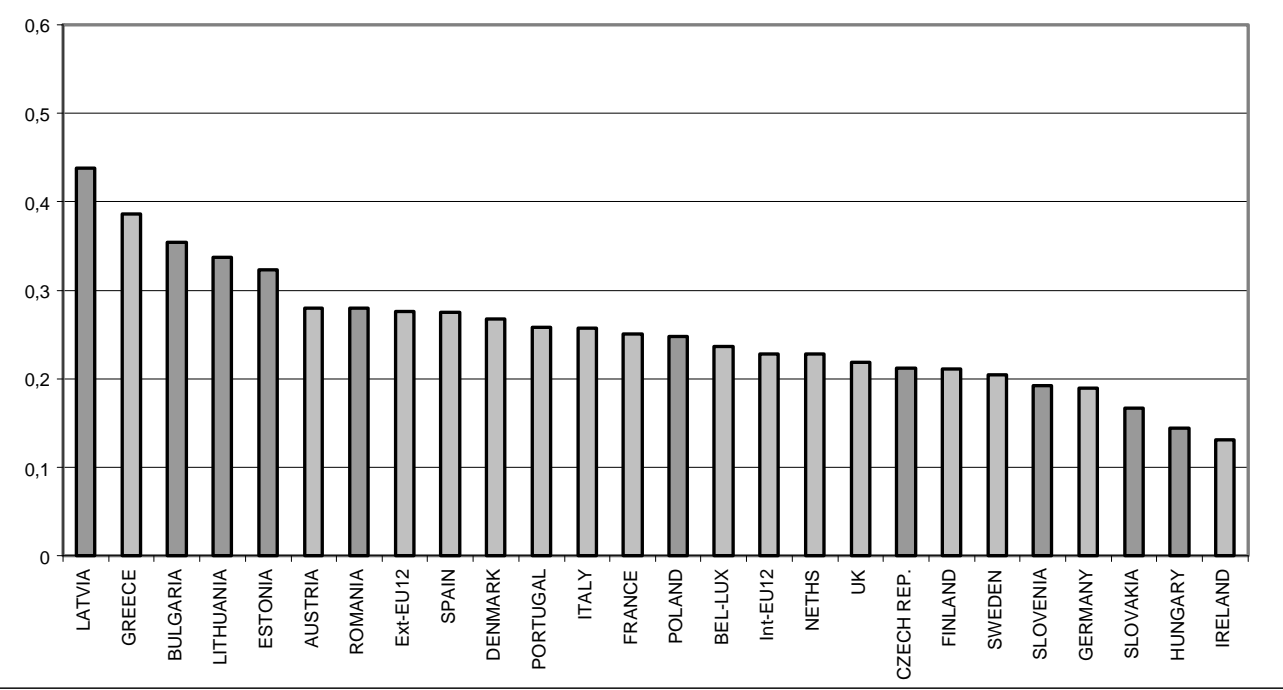




\section{Figure 3}
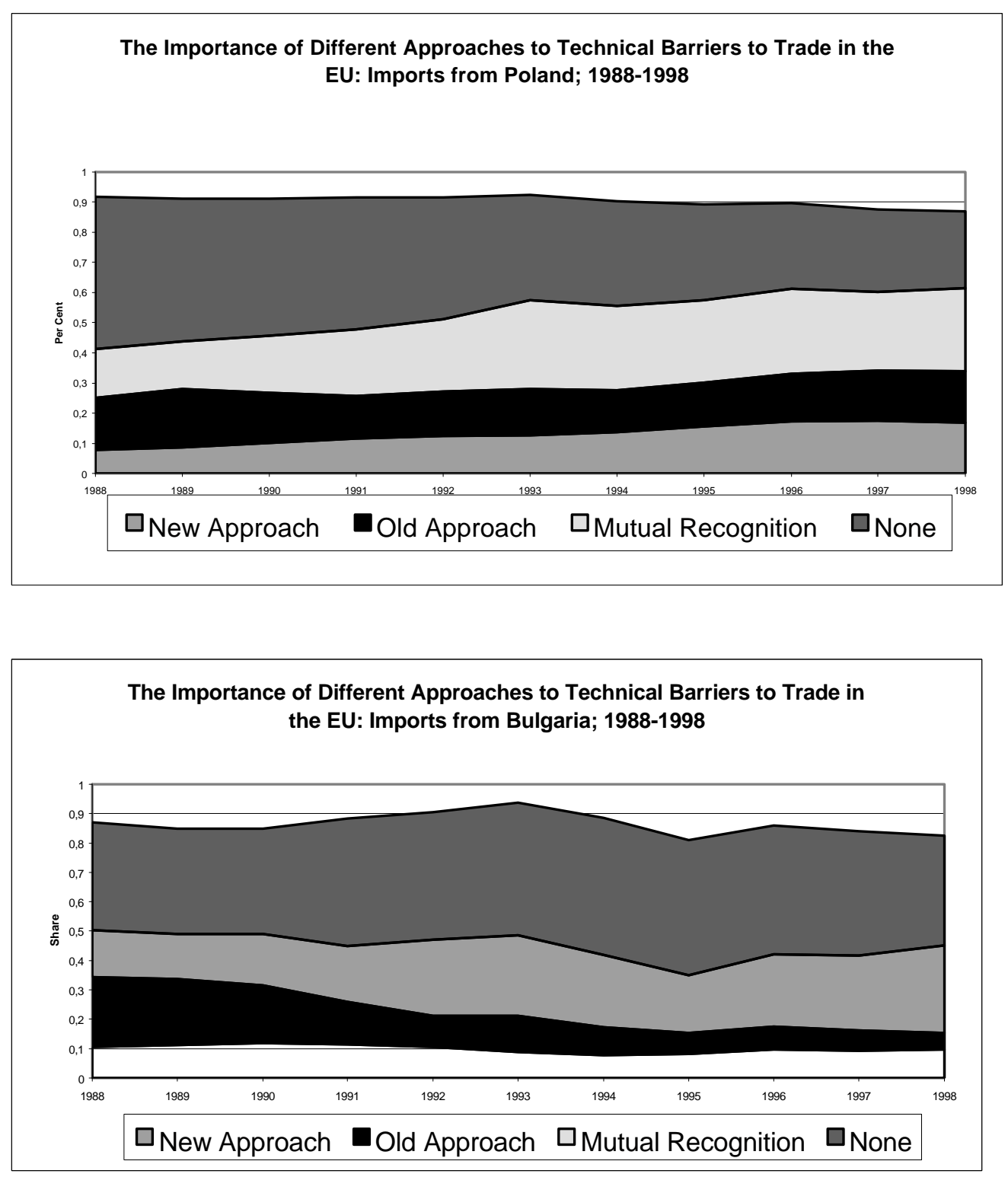

The Importance of Different Approaches to Technical Barriers to Trade in the EU: Imports from Hungary; 1988-1998
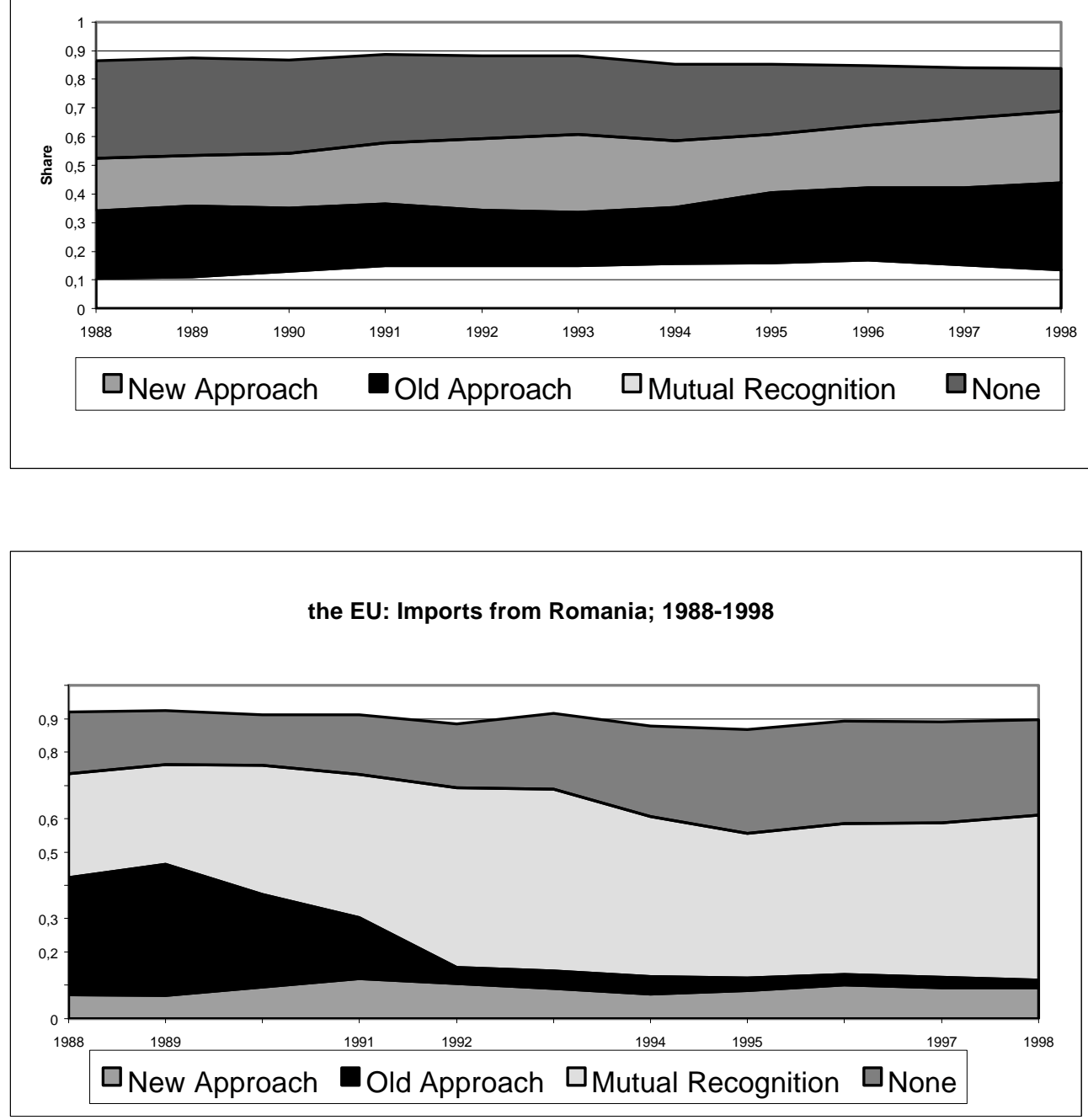
Figure 4 Distribution of Sectoral Revealed Comparative Advantages by Approach to Technical Barriers:
Bulgaria 1998

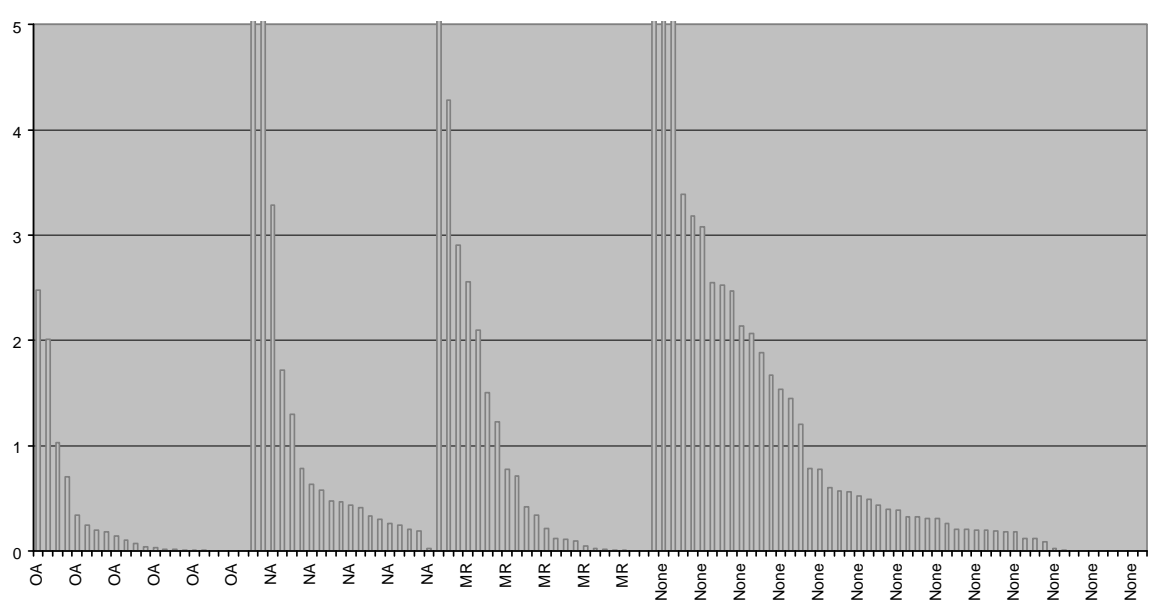

Distribution of Sectoral Revealed Comparative Advantages by Approach to Technical Barriers: Estonia 1998

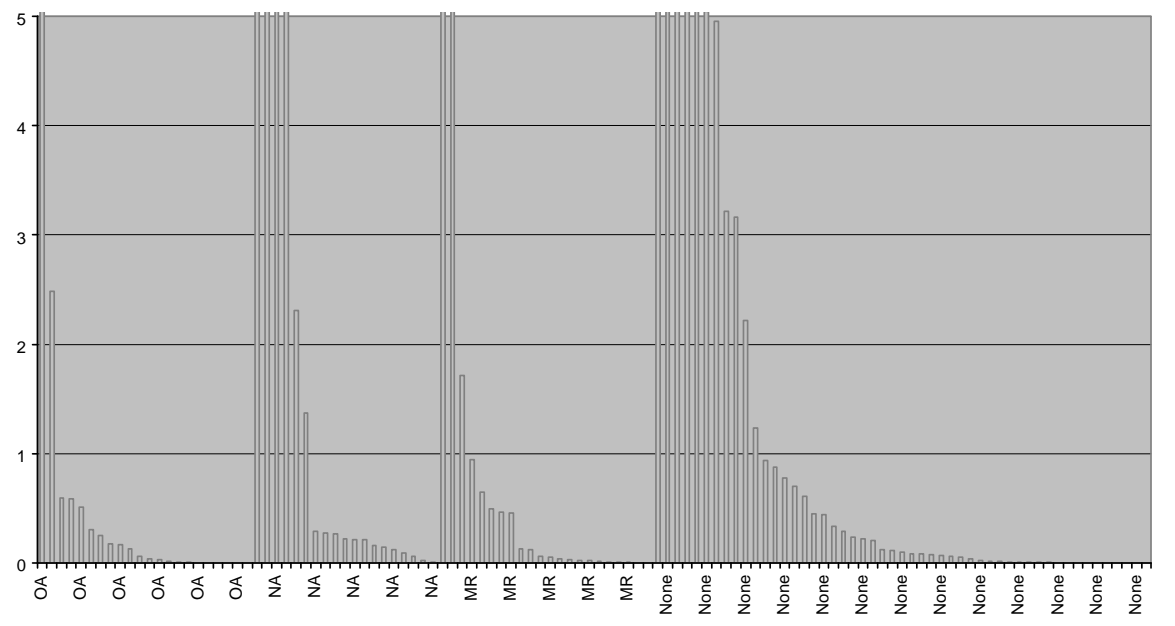

Distribution of Sectoral Revealed Comparative Advantages by Approach to Technical Barriers:

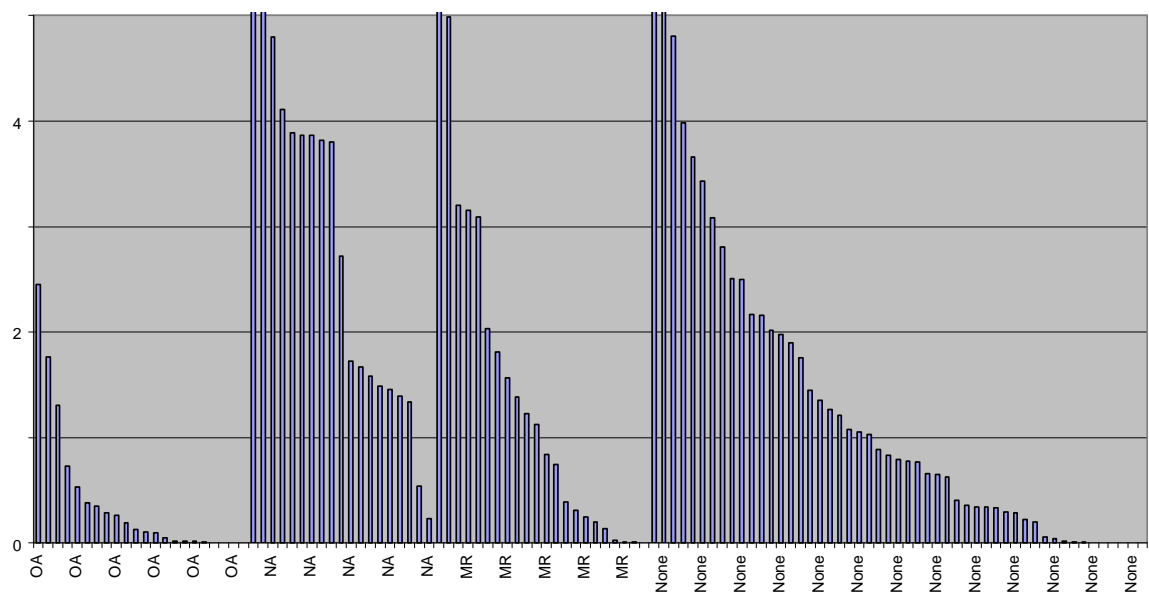

Distribution of Sectoral Revealed Comparative Advantages by Approach to Technical Barriers: Hungary 1998

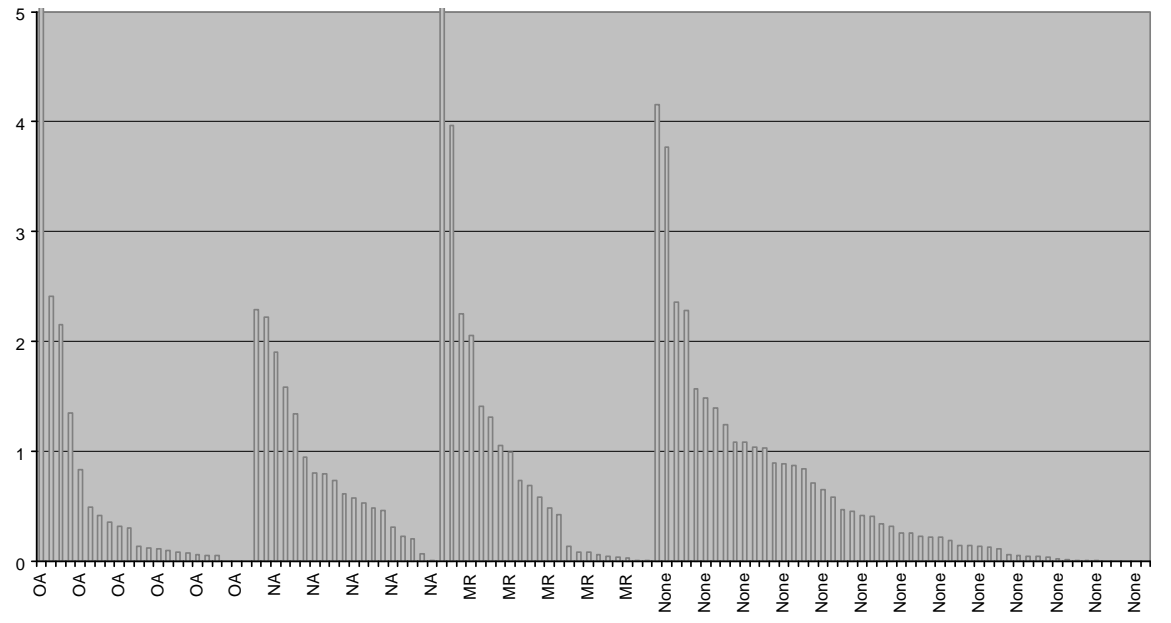


Figure 4

Distribution of Sectoral Revealed Comparative Advantages by Approach to Technical Barriers: Latvia 1998

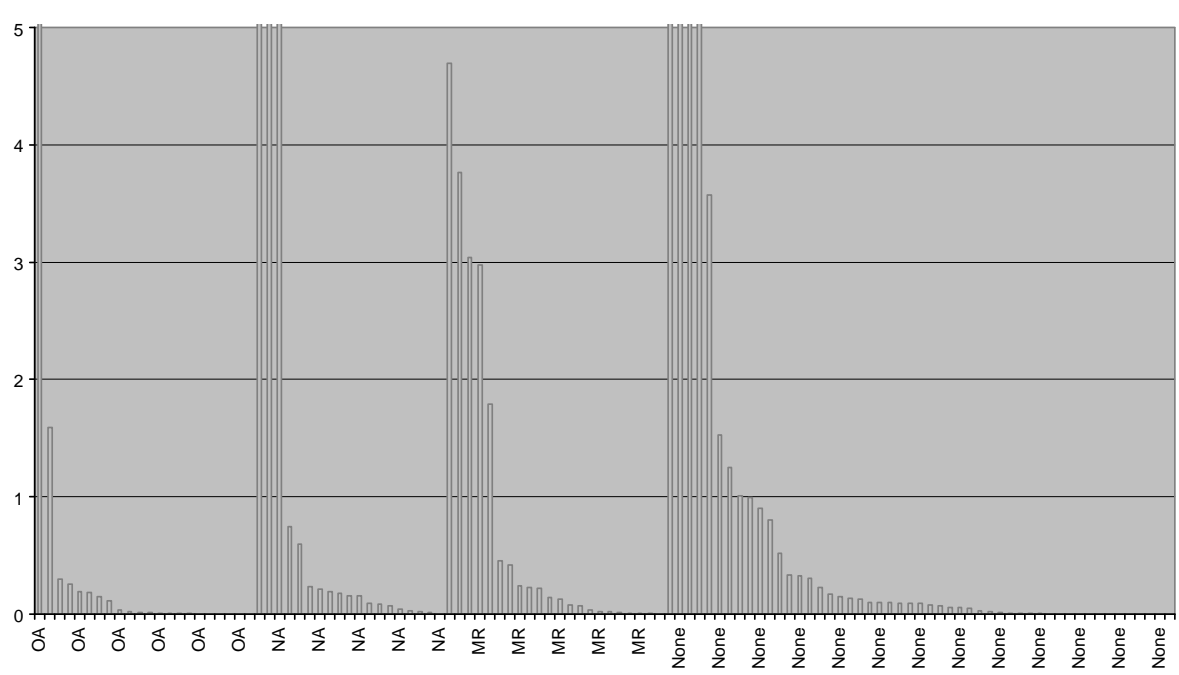

Distribution of Sectoral Revealed Comparative Advantages by Approach to Technical Barriers: Poland 1998

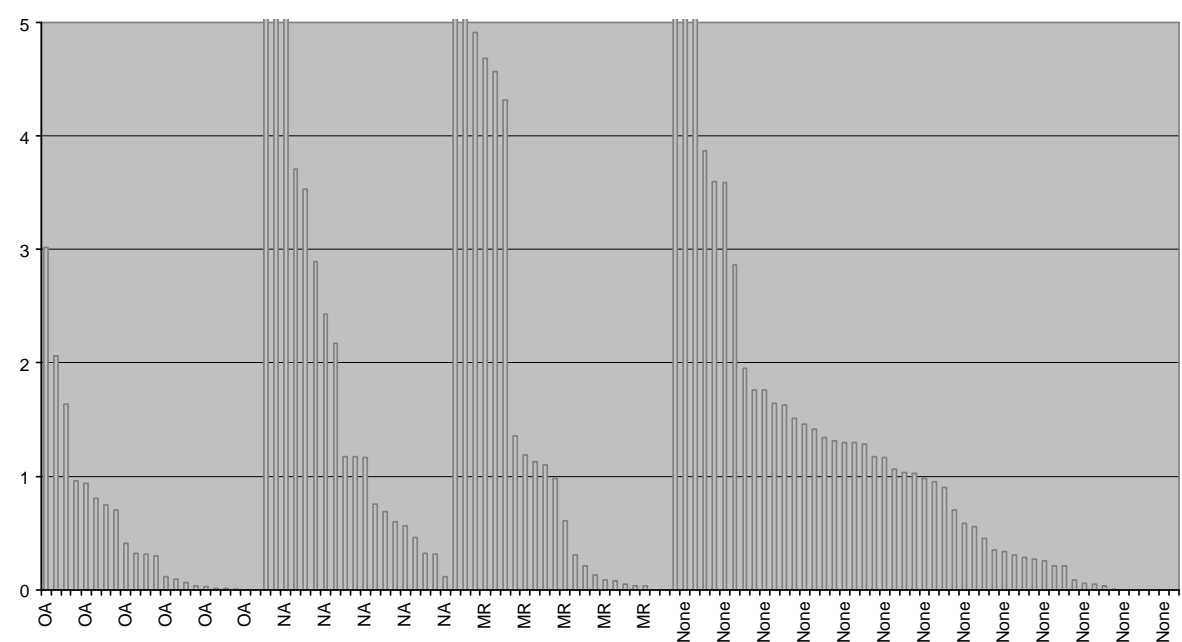

Distribution of Sectoral Revealed Comparative Advantages by Approach to Technical Barriers: Lithuania 1998

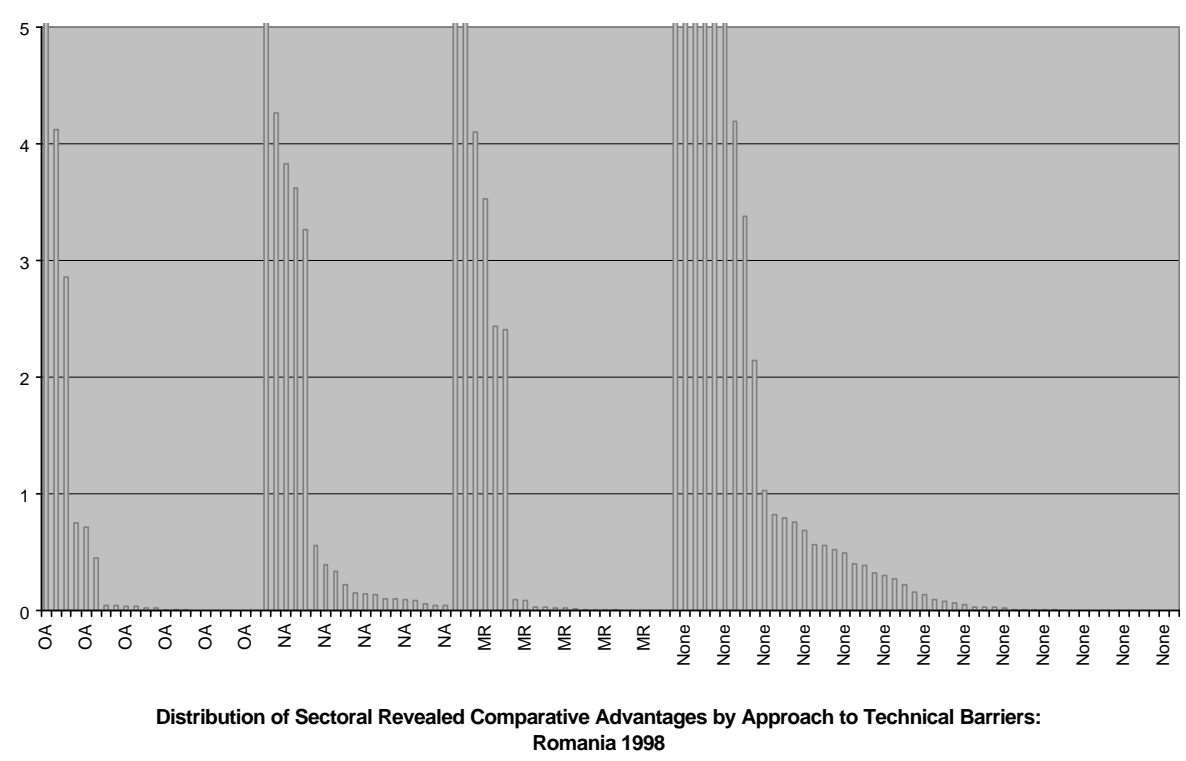

Romania 1998

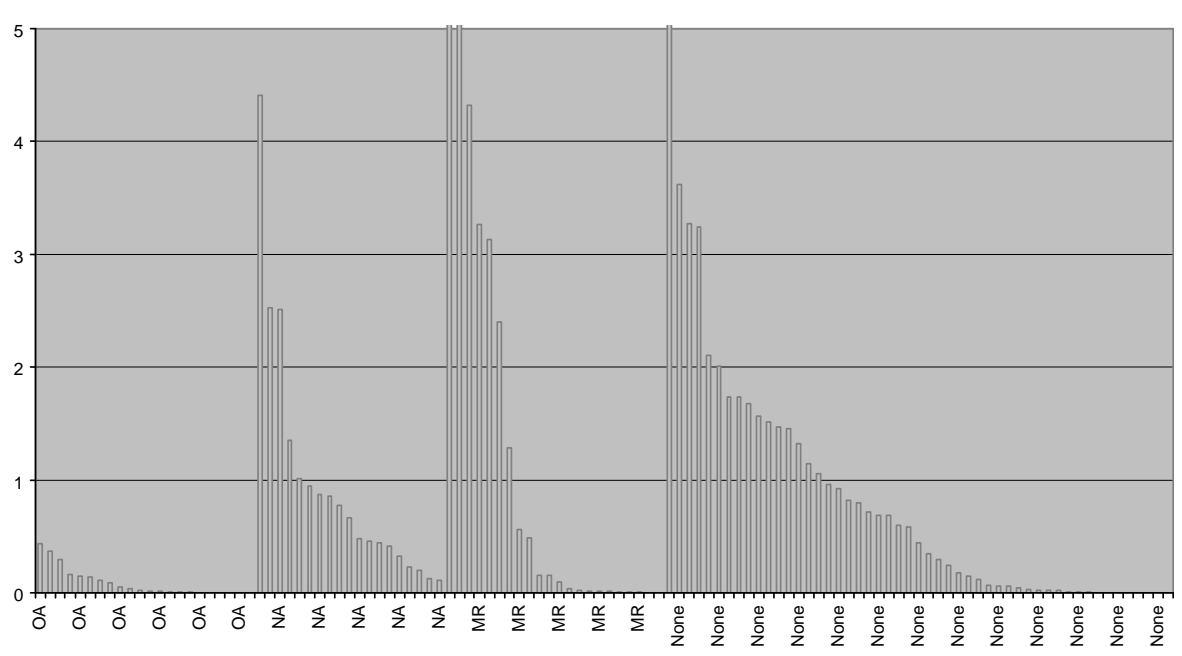


Figure 4

Distribution of Sectoral Revealed Comparative Advantages by Approach to Technical Barriers Slovakia 1998

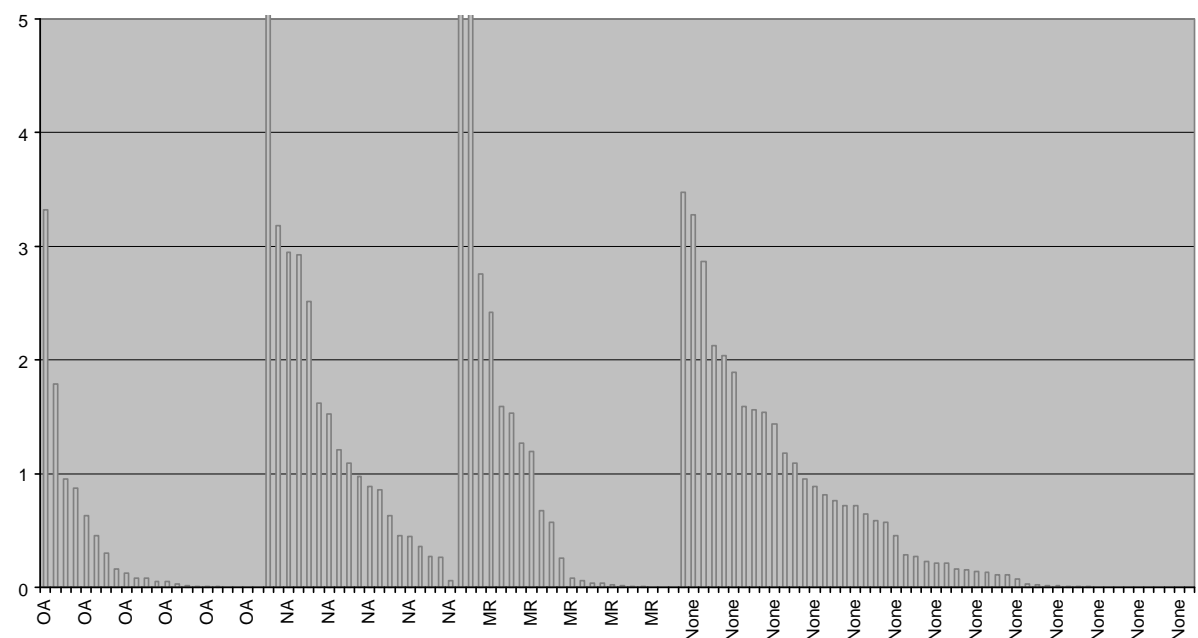

Distribution of Sectoral Revealed Comparative Advantages by Approach to Technical Barriers: Slovenia 1998

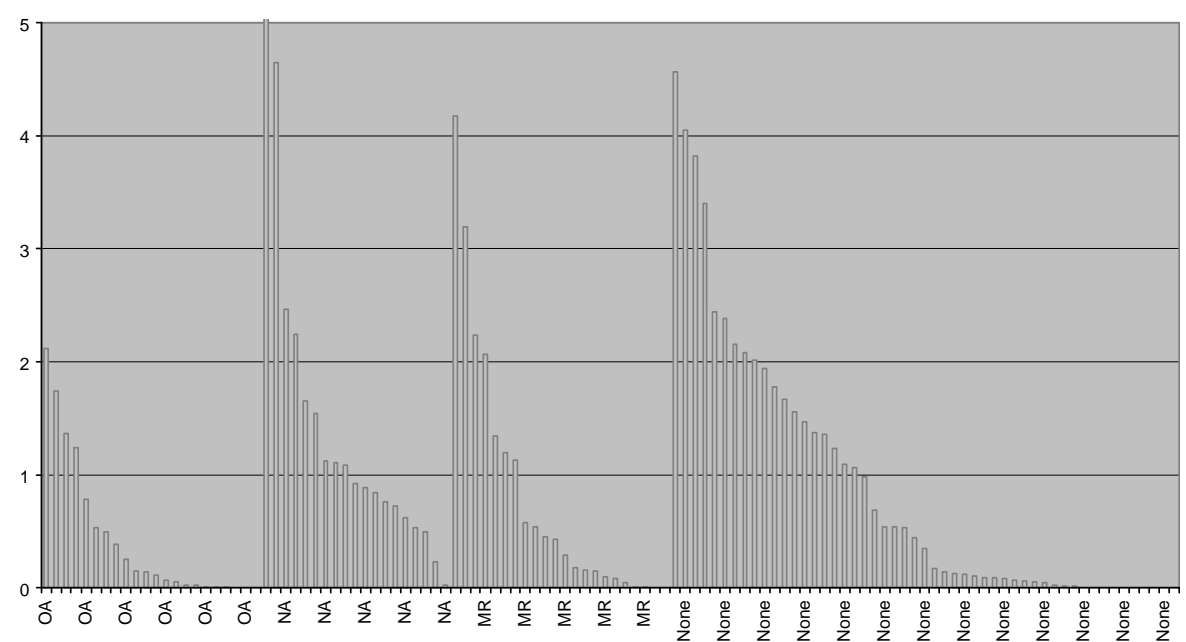


Figure 5a: Similarity of EU Imports of New Approach Products With Intra-EU Average; 1997

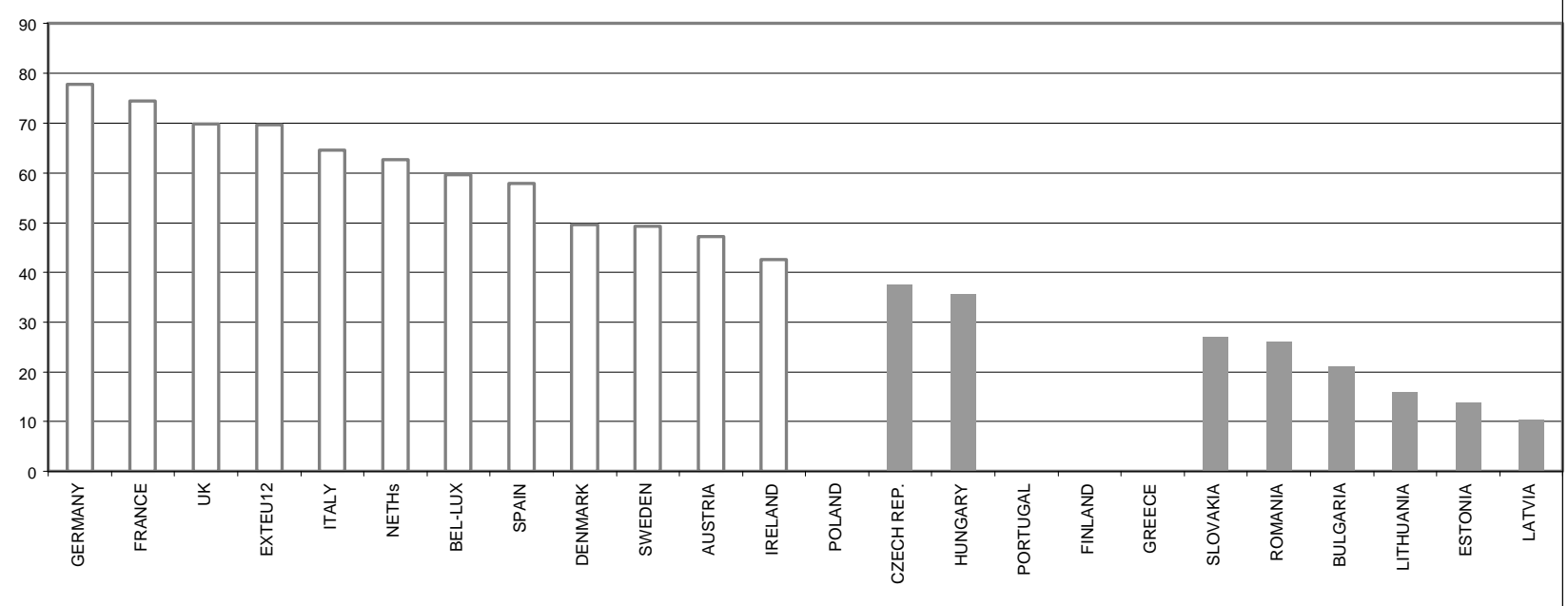

Figure 5b: Similarity of EU Exports of New Approach Products with Intra-EU Average; 1997

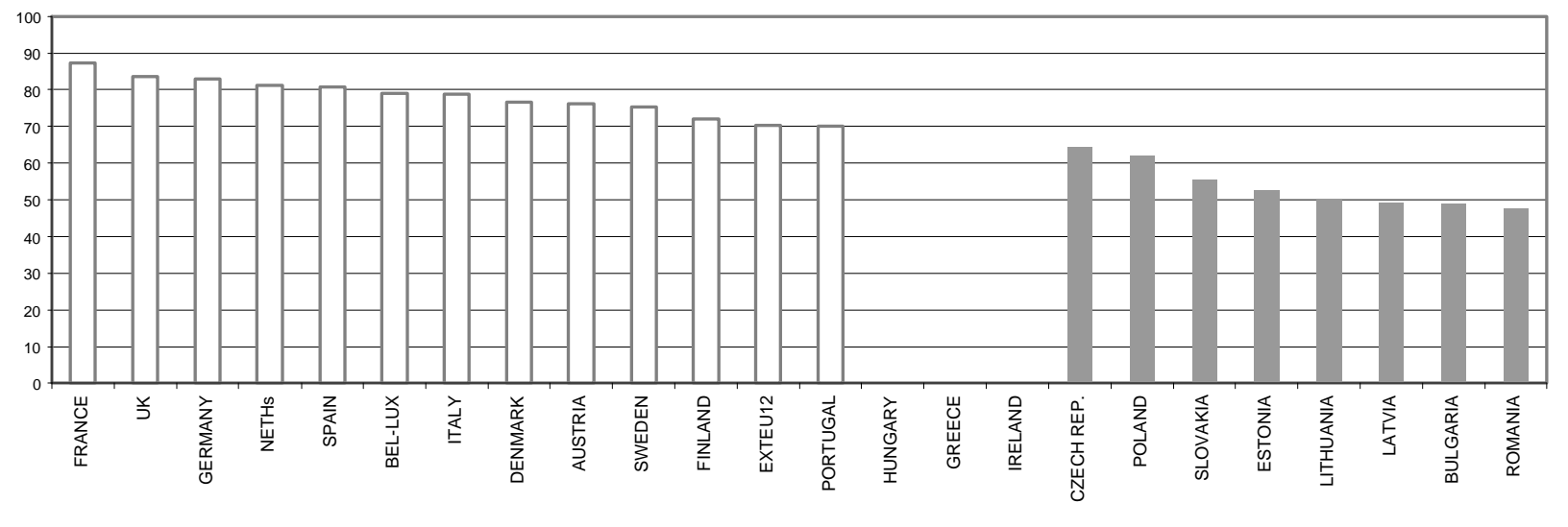

Figure 5c: Similarity of EU Imports and EU Exports of NA Products in 1997

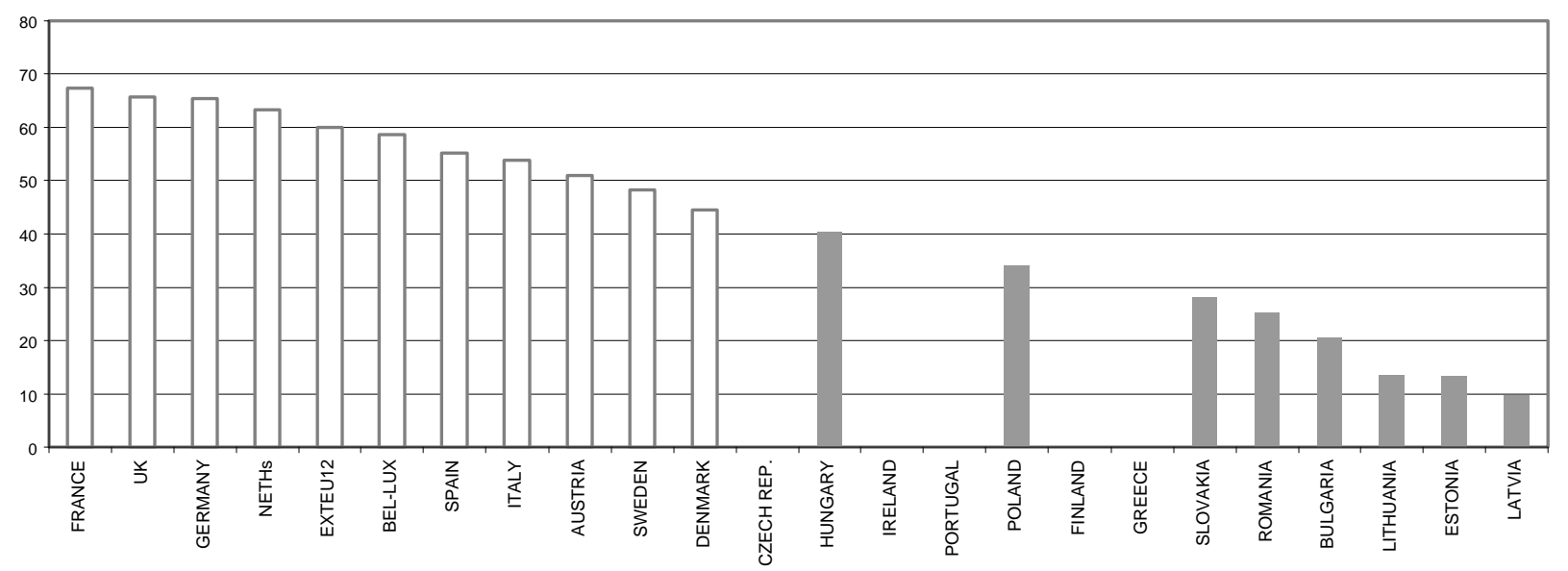


Figure 6a: Similarity of EU Imports of Old Approach Products with Intra-EU Average; 1997

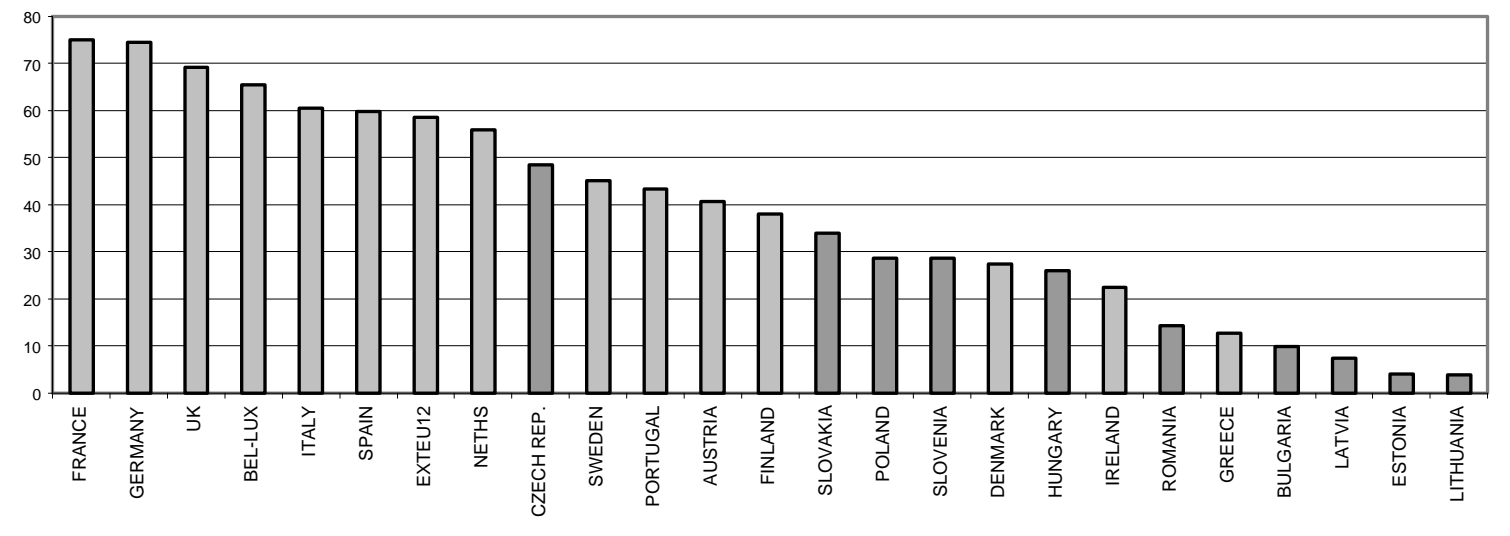

Figure 6b: Similarity of EU Exports of Old Approach Products with Intra-EU Average; 1997

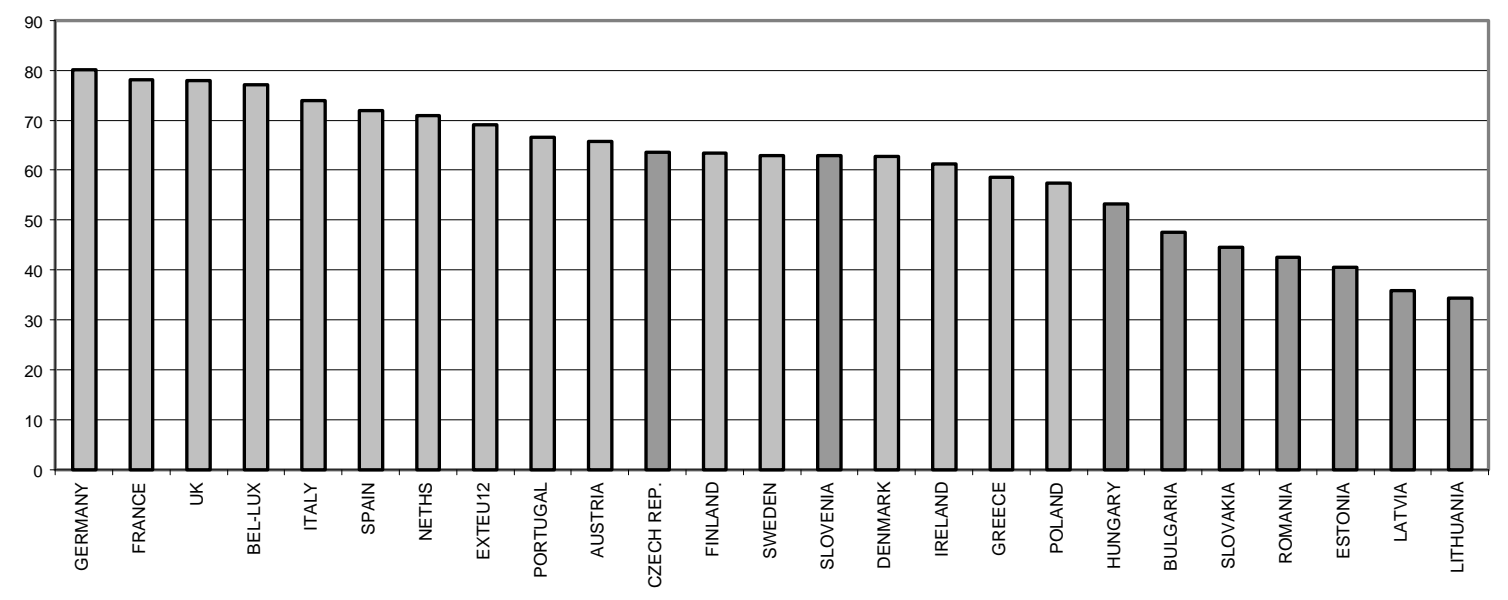

Figure 7c: Similarity of EU Imports and EU Exports of Old Appraoch Products in 1997

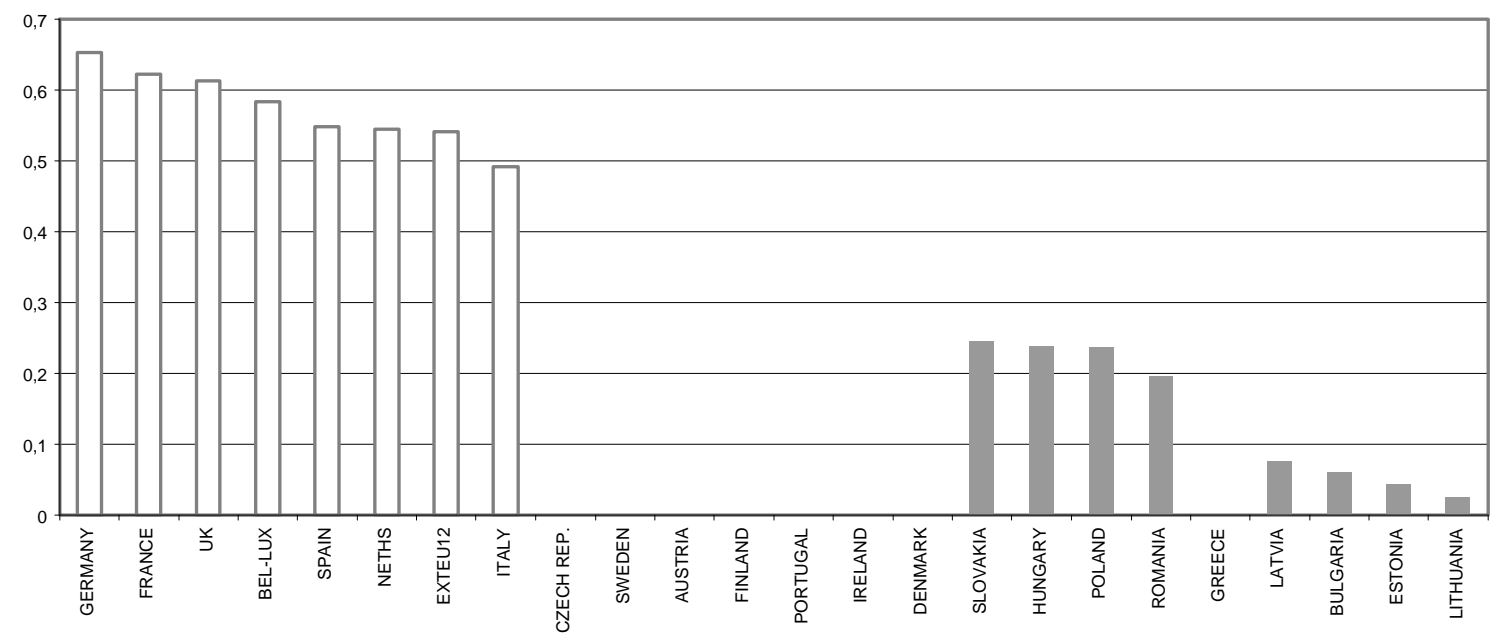




\section{Annex 1. Sources used to Identify Old Approach Products}

\section{Cosmetics}

Directive $76 / 768$ on the approximation of the laws of the Member States relating to cosmetic products.

Commission Decision 96/335/EC establishing an inventory and a common nomenclature of ingredients employed in cosmetic products.

\section{5 products identified (excluding substances)}

\section{Chemicals}

Directive 76/769 on the Approximation of the laws, regulations and administrative provisions of the Member States relating to restrictions on the marketing and use of certain dangerous substances and preparations.

Council Directive 88/379/EEC on the approximation of the laws, regulations and administrative provisions of the Member States relating to the classification, packaging and labelling of dangerous preparations.

Council Directive 73/404 on the approximation of the laws of the Member States relating to Detergents.

Council Directive 76/116 on the approximation of the laws of the Member States relating to Fertilisers.

Council Directive 80/876/EEC on the approximation of the laws of the Member States relating to straight ammonium nitrate fertilisers of high nitrogen content.

Council Directive 92/109/EEC on the manufacture and placing on the market of certain substances used in illicit manufacture of narcotic drugs and psychotropic substances.

Council Directive 93/15/EEC on the harmonisation of the provisions relating to the placing on the market and supervision of explosives for civil uses.

Database RISC: "Chemical Sector Information Network", provided by the European Commission (Mr. Alain Van Raek)

\section{2 substances identified}

\section{Motor Vehicles}

Council Directive 70/156/EEC on the approximation of the laws of the Member States relating to the type-approval of motor vehicles and their trailers and Amendment 92/53/EEC.

Database 'RACE: réglementation automobile communauté européene, June 1999. 
338 products ( vehicles + accessories )

\section{Foodstuffs}

Council Directive 79/112 and COM (1999)113 final on the approximation of the laws of the Member States relating to the labelling, presentation and advertising of foodstuffs.

\section{5 products}

\section{Pharmaceuticals}

Council Directive 65/65EEC on the approximation of provisions laid down by law, regulation or administrative action relating to proprietary medicinal products.

'Essential Drugs' WHO Drug Information Vol. 13, No. 4, 1999

\section{3 products}




\section{Annex 2. Sources used to identify "New Approach" Products}

Low Voltage - Directive 73/23/EEC

Simple Pressure Vessels - Directives 87/404/EEC and 90/488/EC

Safety of Toys - 88/378/EEC

Construction products - 89/106/EEC

Electromagnetic compatibility - 89/336/EEC, 92/31/EC and 98/13/EC

Machinery - 98/37/EC

Personal protective equipment - 89/686/EEC, 93/95/EEC and 96/58/EC

Non-automatic weighing instruments - 90/384/EEC

Active implantable medical devices - 90/385/EEC

Appliances burning gaseous fuels - 90/396/EEC

Telecommunications Terminal Equipment and Satellite Earth Station Equipment 98/13/EC

New hot-water boilers fired with liquid or gaseous fuels - 92/42/EEC

Explosives for civil uses - 93/15/EEC

Medical devices - 93/42/EEC

Equipment explosive atmospheres - 94/9/EC

Recreational Craft - 94/25/EC

Packaging and packaging waste -94/62/EC

Lifts - 95/16/EC

Interoperability of trans-European high-speed rail system - 96/48/EC

Energy efficiency requirements for household electric refrigerators, freezers and combinations thereof $-96 / 57 / \mathrm{EC}$

Marine equipment - 96/98/EC

Pressure equipment - 97/23/EC

In vitro diagnostic medical devices - 98/79/EC

Radio Equipment and Telecommunications Terminal Equipment and the Mutual Recognition of their conformity - 1999/5/EC 